\title{
Pendingin Termoakustik Menggunakan Stack Bahan Alami: Berpori Teratur (Batang Padi) dan Berpori Acak (Gambas)
}

\author{
Qanitatul Hidayah, Masano, Ikhsan Setiawan and Agung Bambang S.U.*
}

\begin{abstract}
Ringkasan
Telah dilakukan penelitian mengenai pengaruh stack berbahan organik terhadap perubahan suhu pada sistem pendingin termoakustik. Penelitian ini menggunakan dua jenis stack berbahan organik, yaitu batang padi dan gambas (Luffa acutangula). Pada pendingin termoakustik gelombang berdiri, frekuensi resonansi mengalami pergeseran akibat keberadaan stack. Hasil yang diperoleh adalah perubahan suhu yang terjadi pada tandon panas dan dingin selama pengoperasian pendingin termoakustik. Untuk jenis bahan stack gambas dan batang padi memiliki panjang optimum sama, yaitu $8 \mathrm{~cm}$ dengan penurunan suhu masing-masing sebesar $(11,7 \pm 0,1)^{\circ} \mathrm{C}$ dan $(8,1 \pm 0,1)^{\circ} \mathrm{C}$ pada daya optimum $60 \mathrm{~W}$.
\end{abstract}

Kata Kunci : termoakustik, gelombang berdiri, bahan organik.

\begin{abstract}
It has been researched in order to determine the influence of organic stack on the temperature changes in a standing wave thermoacoustic refrigerator system. This study used two types of organic material stack, namely rice trunks and sponge gourd (Luffa acutangula). On a standing wave of thermoacoustic refrigerator, the resonance frequency have shifted as consequence of existence of the arbitrarily stack. As a result is the decreasing temperature on the both reservoirs (hot and cool reservoirs). For the sponge gourd and the rice trunk which have the same optimum length $(8 \mathrm{~cm})$, the decrease temperature is around $(11,7 \pm 0,1)^{\circ} \mathrm{C}$ and $(8,1 \pm$ $0,1)^{\circ} \mathrm{C}$ respectively on the optimum power of $60 \mathrm{~W}$.
\end{abstract}

Keywords: thermoacoustics; standing waves; organic material

\section{Pendahuluan}

Penelitian ini merupakan kesinambungan, inovasi dan pengembangan dari penelitian-penelitian termoakustik sebelumnya yang telah dilakukan oleh pengusul dan kawan-kawan[5][6][7][13]. Pada penelitian terdahulu, pengusul dan kawan-kawan telah membangun sebuah sistem pendingin termoakustik menggunakan resonator silindris. Dalam hal ini telah diselidiki pengaruh variasi parameternya yaitu variasi frekuensi[2], variasi posisi stack dalam silinder resonator[10], variasi diameter resonator[12], dan variasi amplitudo bunyi[20] terhadap kinerja sistem pendingin tersebut. Disamping itu 'juga telah diteliti

${ }^{*}$ Correspondence: agungbambang@ugm.ac.id

Department of Physics, Universitas Gadjah Mada, Sekip Utara PO BOX BLS 21, 55281 Yogyakarta, Indonesia

Full list of author information is available at the end of the article

${ }^{\dagger}$ Equal contributor pengaruh kinerja sistem menggunakan stack berpori acak berbahan logam[3].

Dengan banyaknya parameter yang menentukan kinerja pendingin termoakustik, maka pada penelitian ini dibatasi yaitu pengaruh perubahan suhu dengan penggunaan stack bahan alami: berpori teratur (batang padi) dan berpori acak (gambas) serta adanya penukar kalor tambahan yang dialiri cairan untuk mengurangi arus balik kalor dalam resonator.

Dari uraian di atas, maka tujuan khusus dari penelitian ini adalah: meneliti pengaruh kinerja termoakustik dengan adanya stack bahan alami:batang padi dan gambas serta penukar kalor tambahan terisi cairan yang mengalir dalam resonator (bagian panas).

Meskipun pada dasarnya masih banyak parameter yang menentukan kinerja dan efisiensi pendingin termoakustik, antara lain: jenis dan tekanan gas 
dalam resonator, bahan stack, kinerja loud-speaker, konfigurasi resonator, dan lain-lain[14][15][11][19][8]. Secara eksperimental konversi energi termoakustik telah didemonstrasikan oleh Biwa dkk (2004), sedangkan Yazaki dkk (2002) mendemonstrasikan sebuah prototipe pendingin akustik yang menggunakan siklus Stirling. Secara teoretis dan eksperimental tentang karakteristik frekuensi pada pendingin termoakustik telah diperoleh suatu pita frekuensi yang sempit yang membangkitkan osilasi kuat dan menimbulkan efek termoakustik [16].

Dengan adanya penelitian yang bertahap dan berkesinambungan, diharapkan pada akhir tujuan jangka panjang yang ingin diperoleh adalah terwujudnya piranti pendingin termoakustik yang memiliki efisiensi tinggi sehingga layak diproduksi secara komersial dan masal.

Secara umum, telah dipaparkan bahwa urgensi penelitian ini terletak pada terbentuknya alat pendingin yang ramah lingkungan karena menggunakan udara (alat pendingin non-freon). Selain sifatnya yang ramah lingkungan karena menggunakan zat pendingin yang melimpah dan tak habis (inexhaustible), seperti udara atau gas mulia, pendingin termoakustik ini menggunakan gelombang bunyi dalam proses pendinginan. Adapun secara khusus, pentingnya penelitian ini adalah terletak pada kinerja stack bahan alami (batang padi dan gambas) serta ditambahkan penukar kalor dengan aliran cairan dalam proses transfer kalor untuk memperoleh pendinginan yang lebih baik atau dengan kata lain diharapkan kinerja sistem meningkat.

\section{Teori Dasar}

Gelombang bunyi berdiri terjadi dari hasil superposisi antara gelombang datang dan gelombang pantul yang mempunyai frekuensi dan amplitudo sama bertemu dalam arah berlawanan. Gelombang berdiri dapat diilustrasikan seperti gelombang pada tali dengan salah satu ujung tali terikat penyangga dan gelombang yang terbentuk akibat sentakkan pada ujung tali lainnya. Dalam hal ini akan timbul lengkungan yang merambat sepanjang tali. Gelombang akan dipantulkan secara berturut turut dan simpangan yang dihasilkan oleh tali menjadi superposisi dari dua gelombang tersebut. [9]

Pada pipa tertutup, gelombang berdiri untuk mode dasar longitudinal dari titik perut ke simpul yang berdekatan, merupakan seperempat dari panjang gelombang. Oleh karena itu, panjang gelombang untuk mode normal pertama adalah $4 \mathrm{~L}$, dan frekuensi dasar $f_{1}=v / 4 L$. Adapun pada mode normal pertama, gelombang longitudinal berdiri antara dua titik perut yang berdekatan, merupakan setengah panjang gelombang. Dengan demikian, panjang gelombang adalah dua kali panjang pipa, dan frekuensi dasar adalah $f_{1}=v / 2 L$.

Selain melibatkan gelombang longitudinal, dalam termoakustik juga melibatkan system pendingin.

Prinsip kerja dari mesin pendingin pada dasarnya kebalikan dari mesin kalor (Gambar 1). Pada mesin pendingin, kerja $W$ digunakan untuk menghasilkan aliran kalor terhadap gradien suhu, menyerap kalor tandon dingin $Q_{c}$ pada suhu rendah $T_{c}$ dan melepaskan kalor tandon panas $Q_{H}$ pada suhu tinggi $T_{H}$ (Gambar 1b). Sesuai dengan hukum kedua termodinamika yang menyatakan bahwa tidak mungkin memindahkan kalor dari tandon dingin ke tandon panas tanpa membutuhkan tenaga lain. Oleh karena itulah pada siklus mesin pendingin membutuhkan kerja $W$ dari luar untuk transfer kalor

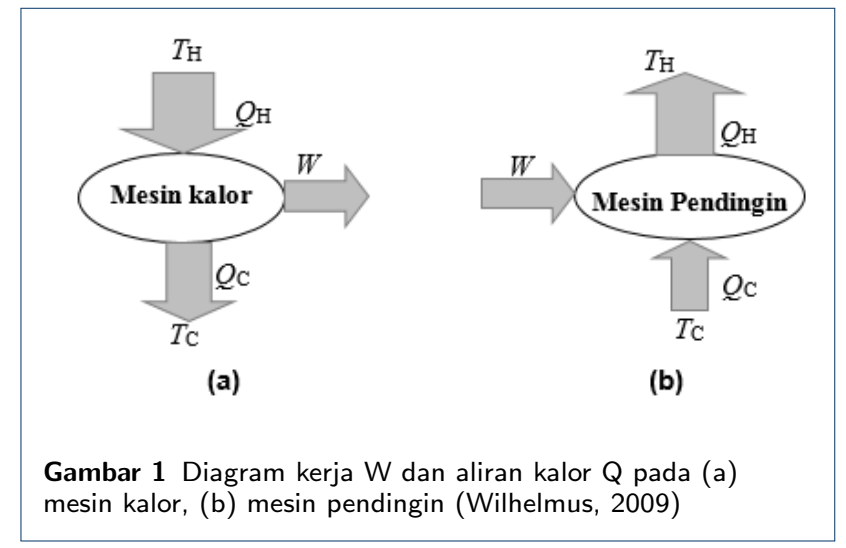

Adapun Termoakustik (thermoacoustic) adalah suatu bidang yang berhubungan dengan fenomena fisis dimana perbedaan suhu dapat menghasilkan gelombang bunyi atau sebaliknya gelombang bunyi menghasilkan perbedaan suhu [13]. Pada dasarnya termoakustik menggabungkan cabang akustik dan termodinamika bersama-sama untuk memindahkan kalor dengan menggunakan bunyi. Osilasi yang terjadi pada gelombang bunyi atau akustik dalam gas adalah osilasi tekanan dan gerakan, sehingga osilasi tersebut mengakibatkan perubahan suhu. Jika bunyi merambat dalam kanal-kanal kecil (stack), kalor yang berosilasi akan mengalir ke dan dari dinding-dinding kanal. Gabungan seluruh osilasi tersebut menghasilkan suatu efek termoakustik. Alat yang digunakan untuk menimbulkan efek termoakustik disebut mesin termoakustik. (Gambar 2)

Pada awalnya suhu dan tekanan pada kedua tandon sama. Akan tetapi setelah pendingin termoakustik dioperasikan, maka gelombang bunyi berosilasi, sehingga paket gas dalam stack akan bergerak ke kiri. Paket gas yang bergerak ke kiri akan termampatkan 
dan tekanan meningkat. Paket gas yang termampatkan menjadi lebih panas daripada dinding stack di dekatnya sehingga melepaskan kalor ke stack dan volume paket gas akan menyusut, proses ini terjadi pada tahap kedua. Tahap ketiga, paket gas bergerak kembali ke kanan dimana tekanannya lebih rendah, dalam hal ini paket gas menjadi lebih renggang dan lebih dingin daripada dinding stack di dekatnya, sehingga paket gas menyerap kalor dari dinding stack dan mengembang. Siklus ini terus berulang dan efeknya adalah transfer kalor dari bagian kanan ke bagian kiri stack. Bagian yang terambil kalornya disebut tandon dingin sedangkan yang bertambah kalornya disebut tandon panas [13].

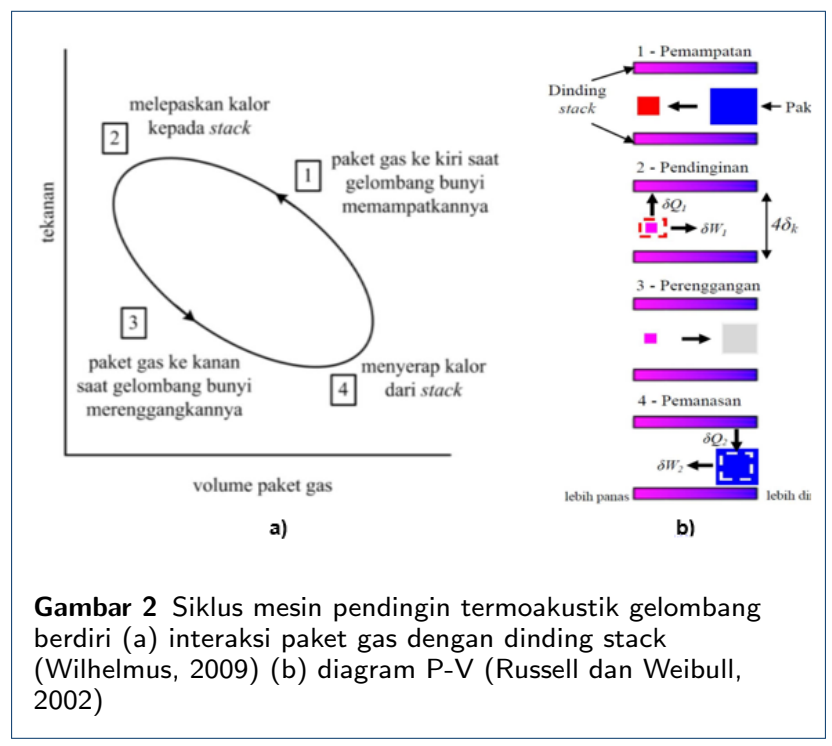

\section{Metode Penelitian}

Seperti telah disebutkan di Latar Belakang bahwa penelitian ini merupakan kelanjutan dari penelitian-penelitian sebelumnya secara bertahap dan berkesinambungan.

Dalam penelitian ini, dimulai dengan Tahap Persiapan, yaitu pengadaan bahan stack organik dengan bentuk pori acak (gambas kering) dan pori teratur (batang Padi). (Gambar 3).

Pada Tahap Pelaksanaan, yaitu penyusunan piranti pendingin termoakustik dan sistem pengukurannya, menggunakan stack organik termasuk penukar kalor tambahan yang tersusun seperti Gambar 4.

Susunan sistem (Gambar 4) terdiri dari resonator pipa PVC bentuk silindris yang di dalamnya terdapat sebuah stack organik yang berfungsi sebagai penukar kalor utama dan yang membentuk ruang di sebelah kanan stack merupakan reservoir kanan (tandon dingin) dan di sebelah kiri stack merupakan reservoir

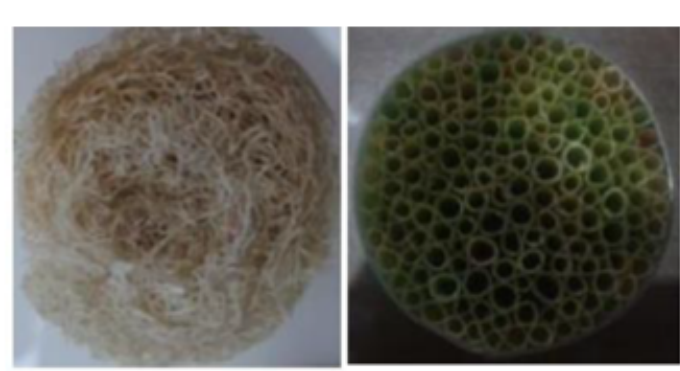

Gambar 3 Penampang bahan stack Gambas dan Batang Padi. (Hidayah, 2014)

kiri (tandon panas). Suhu kedua reservoir diukur masing-masing dengan menggunakan termometer digital. Dalam hal ini dapat teramati seberapa besar perubahan suhu tandon dan seberapa besar beda suhu antara tandon dingin - tandon panas. Eksperimen selanjutnya dilakukan dengan memasang penukar kalor tambahan pada tandon panas (dekat stack bagian kiri). Dalam hal ini akan diamati seberapa besar perubahan suhu ke dua tandon, sehingga dapat dibandingkan perubahan suhu dengan ada tidaknya penukar kalor tambahan tersebut.

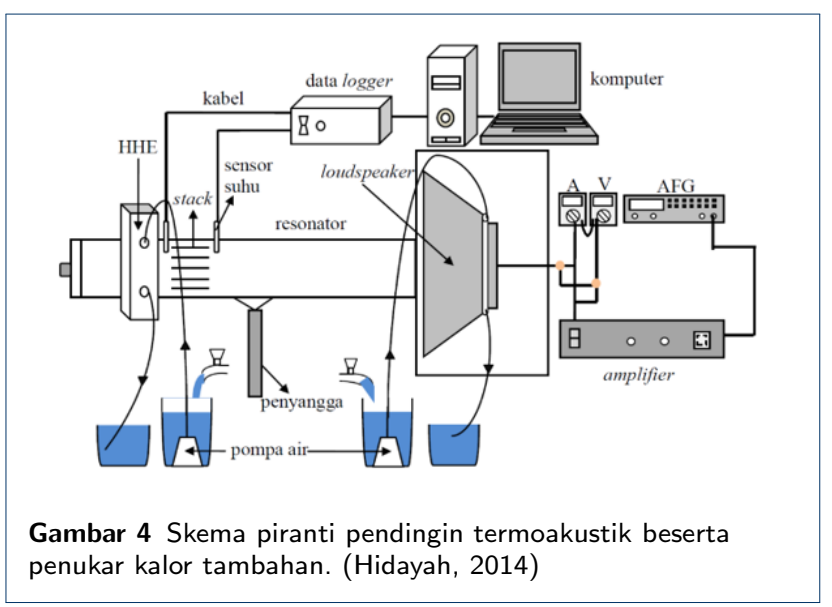

Pada Tahap ke tiga, dilakukan Tahap Analisis Hasil. Pada tahap ini Kinerja piranti termoakustik ini dapat dilihat dari daya pendinginan yang dimilikinya dan tercermin dari seberapa besar penurunan suhu reservoir dingin yang dapat dicapainya. Oleh karena itu, data hasil eksperimen yang telah diperoleh akan dianalisis dengan metode grafik sebagai berikut: a). Grafik suhu yang memperlihatkan suhu pada reservoir dingin dan reservoir panas sebagai fungsi waktu. Dalam hal ini melukiskan proses penurunan suhu udara reservoir dingin (juga kenaikan suhu reservoir panas) dengan berjalannya waktu pengoperasian piranti, meliputi laju penurunan suhu 
dan seberapa besar penurunan suhu tersebut dicapai. b). Grafik antara penurunan suhu maksimum versus waktu dengan adanya medium penukar kalor yang akan memperlihatkan kecenderungan ketergantungan penurunan suhu terhadap medium penukar kalor ini.

Adapun Luaran dan Indikator berujud Luaran yang diharapkan dari penelitian yaitu sebuah piranti pendingin termoakustik yang menggunakan stack organik dan penukar kalor tambahan bercairan. Indikatornya adalah daya pendinginan (penurunan suhu) yang maksimum yang dapat dicapai oleh piranti pendingin termoakustik ini.

\section{Hasil dan Pembahasan}

\subsection{Pengaruh Panjang Stack dengan Variasi Frekuensi terhadap Penurunan Suhu pada Pendingin Termoakustik Gelombang Berdiri}

Penelitian ini dilakukan untuk mengetahui seberapa besar nilai penurunan suhu maksimum di tandon dingin. Ketika pendingin termoakustik gelombang berdiri dioperasikan pada frekuensi tertentu, maka teramati penurunan suhu tandon kanan menjadi dingin dan kenaikan suhu pada tandon kiri yang menjadi panas. Hal tersebut menunjukkan bahwa terjadi transfer kalor dari tandon dingin ke tandon panas akibat adanya gelombang bunyi.

Pengamatan dilakukan dengan memvariasi frekuensi terhadap masing-masing panjang stack pada jenis bahan yang berbeda (gambas, batang padi, dan serat nanas). Selain memvariasi frekuensinya, penelitian ini juga memvariasi panjang stack dari $6 \mathrm{~cm}$ sampai $8 \mathrm{~cm}$ dengan kenaikan $1 \mathrm{~cm}$. Panjang stack masing-masing bahan divariasi frekuensinya disekitar frekuensi resonansi tabung kosong (tanpa stack). Hal tersebut dilakukan untuk mengetahui apakah keberadaan stack dalam tabung resonator mempengaruhi frekuensi resonansi. Karena frekuensi yang dapat menghasilkan penurunan suhu paling besar terjadi di frekuensi resonansi tabung yang berisi stack. Selain itu, tujuan dari panjang stack yang divariasi adalah untuk mengetahui apakah panjang stack juga akan mempengaruhi pergeseran frekuensi resonansi.

Bahwasanya pada frekuensi $(97 \pm 1) \mathrm{Hz}$ adalah frekuensi resonansi untuk stack gambas $6 \mathrm{~cm}$. Penurunan suhu total di tandon dingin pada frekuensi $(97 \pm 1) \mathrm{Hz}$ adalah $(11,3 \pm 0,1){ }^{\circ} \mathrm{C}$. Dalam waktu lima menit pertama pengoperasian alat, terjadi perubahan suhu tandon yang relatif cepat, penurunan suhu tandon dingin mencapai $(9,3 \pm 0,1){ }^{\circ} \mathrm{C}$ (sebelum HHE dialiri air), sedangkan kenaikan suhu tandon panas mencapai $(4,1 \pm 0,1){ }^{\circ} \mathrm{C}$ (sebelum HHE dialiri air). Namun, menit keempat tandon dingin sudah mulai jenuh atau tidak bisa turun lagi, sedangkan tandon

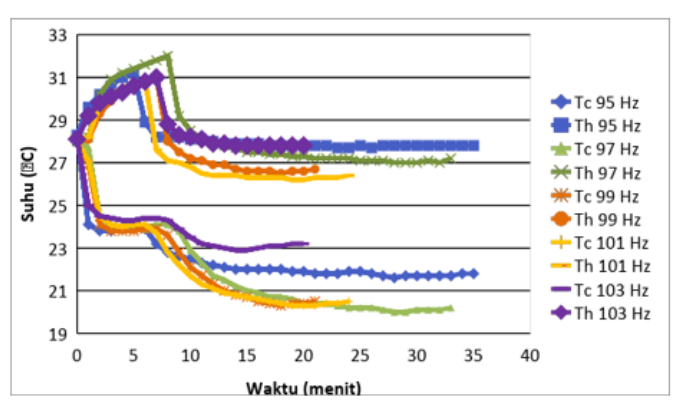

Gambar 5 Grafik perubahan suhu dan waktu dengan variasi frekuensi pada panjang stack batang padi $8 \mathrm{~cm}$. (Hidayah, 2014)

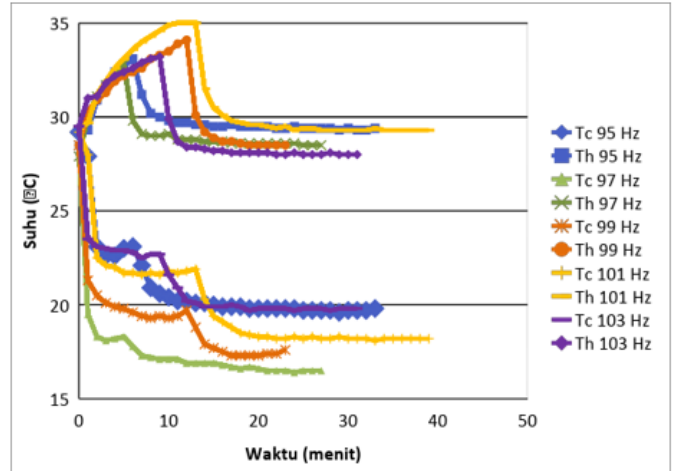

Gambar 6 Grafik perubahan suhu dan waktu dengan variasi frekuensi pada panjang stack gambas $8 \mathrm{~cm}$. (Hidayah, 2014)

panas masih terus naik suhunya akibat pemampatan gas.

Gambar 5 menunjukkan frekuensi $(97 \pm 1) \mathrm{Hz}$ adalah frekuensi resonansi untuk stack batang padi $8 \mathrm{~cm}$ yang menghasilkan penurunan suhu maksimum. Penurunan suhu total yang mampu dicapai adalah $(8,1$ $\pm 0,1){ }^{\circ} \mathrm{C}$. Titik jenuh tandon dingin tercapai pada menit kedelapan saat perangkat dioperasikan, dengan penurunan suhunya sebesar $(4,2 \pm 0,1){ }^{\circ} \mathrm{C}$ sebelum HHE dialiri air.

Pada Gambar 6 menunjukkan frekuensi resonansi yang menghasilkan penurunan suhu maksimum untuk gambas $8 \mathrm{~cm}$ adalah $(97 \pm 1) \mathrm{Hz}$. Penurunan suhu total yang mampu dicapai pada frekuensi $(97 \pm 1) \mathrm{Hz}$ adalah $(11,7 \pm 0,1){ }^{\circ} \mathrm{C}$.

Lima menit pertama pengoperasian alat, terjadi perubahan suhu tandon yang relatif cepat, penurunan suhu tandon dingin mencapai $(10,0 \pm 0,1){ }^{\circ} \mathrm{C}$, sedangkan kenaikan suhu tandon panas mencapai $(4,9$ $\pm 0,1)^{\circ} \mathrm{C}$ sebelum HHE dialiri air.

Panjang optimum stack, yaitu yang menghasilkan penurunan suhu maksimum untuk gambas dan batang 
padi adalah $8 \mathrm{~cm}$. Besarnya penurunan suhu total pada panjang optimum untuk stack gambas dan batang padi adalah $(11,7 \pm 0,1){ }^{\circ} \mathrm{C}$ dan $(8,1 \pm 0,1){ }^{\circ} \mathrm{C}$ dengan frekuensi resonansi $(97 \pm 1) \mathrm{Hz}$.

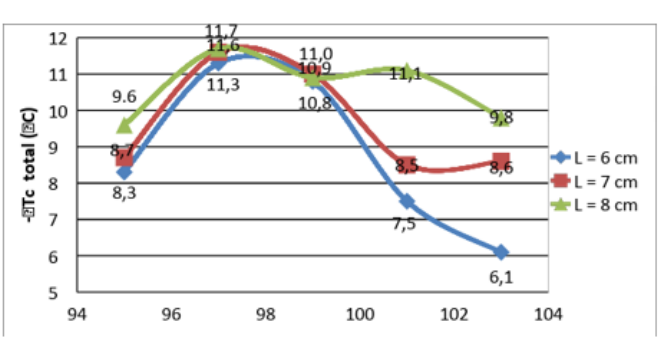

Gambar 7 Grafik penurunan suhu total $\left(\otimes T_{c}\right.$ total) dan frekuensi dengan variasi panjang pada stack gambas. (Hidayah, 2014)

Hasil penurunan suhu total di berbagai frekuensi dapat dilihat pada Gambar 7 dan Gambar 8 untuk masing-masing panjang stack gambas dan batang padi. Gambar 7 dan Gambar 8 terlihat bahwa semakin besar panjang stack yang digunakan, maka penurunan suhunya juga semakin besar. Namun, juga tidak dapat dipastikan bahwa panjang stack yang lebih panjang dari $8 \mathrm{~cm}$ menghasilkan penurunan suhu yang besar (maksimum). Hal ini disebabkan karena pada setiap jenis bahan stack memiliki penurunan suhu optimum yang berbeda-beda. Selain itu, keterbatasan ruang stack juga mempengaruhi besarnya penurunan suhu.

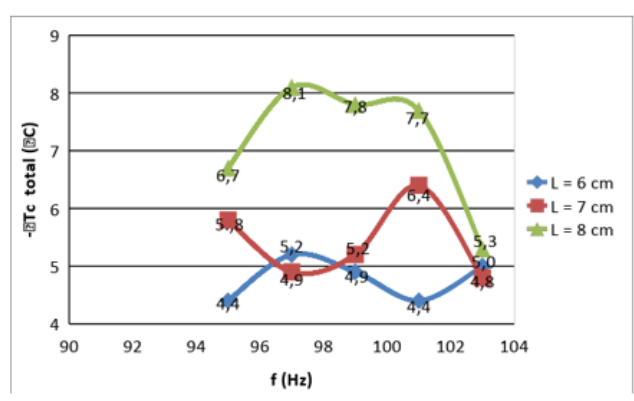

Gambar 8 Grafik penurunan suhu total $\left(\otimes T_{c}\right.$ total) dan frekuensi dengan variasi panjang pada stack batang padi. (Hidayah, 2014)

Diantara penggunaan jenis bahan stack organik, stack batang padi memiliki kelemahan, yaitu tidak tahan lama karena keadaan bahanstack yang tidak kering, cepat busuk karena terlalu lembab dan berjamur. Tetapi batang padi harus dalam keadaan lembab agar pori stack tidak tertutup. Untuk mengantisipasinya, penggunaan stack batang padi diganti setiap 4 hari sekali.
Penelitian sebelumnya untuk stack gambas telah diteliti oleh Candraresita (2013) dan Putri (2013). Hasil penelitian Candraresita (2013) menunjukkan bahwa penurunan suhu stack gambas sebesar $(5,3$ $\pm 0,1){ }^{\circ} \mathrm{C}$ pada panjang optimum $6 \mathrm{~cm}$ dengan menggunakan tegangan 10 volt. Sedangkan penelitian Putri (2013) menunjukkan penurunan suhu maksimum stack gambas $6 \mathrm{~cm}$ sebesar $(7,2 \pm 0,1) \quad{ }^{\circ} \mathrm{C}$ dengan menggunakan CHE yang dipasang $35 \mathrm{~cm}$ dari loudspeaker pada daya $90 \mathrm{~W}$. Penelitian ini menunjukkan stack gambas $6 \mathrm{~cm}$ menghasilkan penurunan suhu maksimum $(11,3 \pm 0,1) \quad{ }^{\circ} \mathrm{C}$ pada daya 60 W. Hasil tersebut jauh lebih besar dibanding dengan penelitian sebelumnya. Hal tersebut dikarenakan penggunaan model penyusunan stack yang berbeda. Ternyata model penyusunan dengan menggulung bahan lebih efektif menghasilkan penurunan suhu maksimum dibanding menyusun satu per satu gambas yang berbentuk lingkaran.

\subsection{Pengaruh Panjang Stack Optimum dengan Variasi Daya Loudspeaker terhadap Penurunan Suhu pada Pendingin Termoakustik Gelombang Berdiri}

Panjang stack optimum pada jenis bahan batang padi dan gambas ditentukan dari frekuensi yang menghasilkan penurunan suhu maksimum. Berdasarkan penelitian sebelumnya, panjang stack optimum gambas dan batang padi adalah $8 \mathrm{~cm}$ dengan frekuensi $(97 \pm 1) \mathrm{Hz}$.

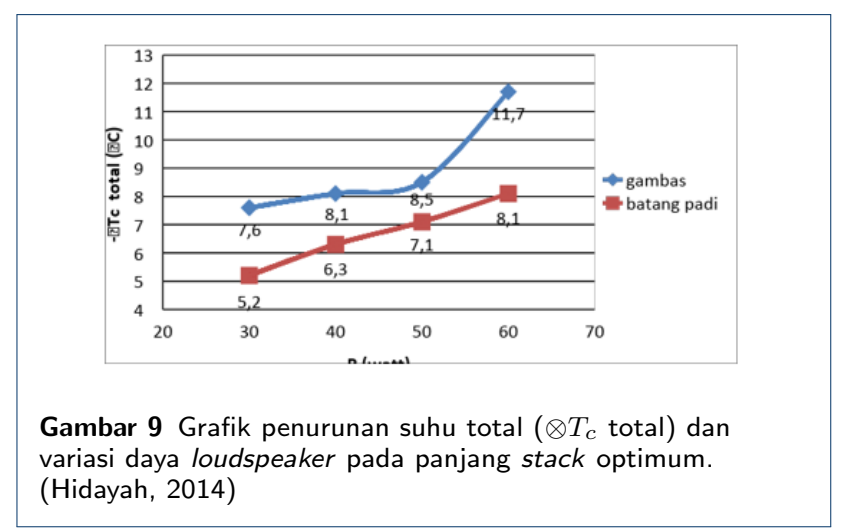

Setelah panjang stack optimum masing-masing bahan didapatkan, kemudian daya loudspeaker divariasikan dari $30 \mathrm{~W}$ sampai $60 \mathrm{~W}$ dengan kenaikan tiap $10 \mathrm{~W}$. Hasil penelitian yang dilakukan adalah daya optimum loudspeaker ketika penurunan suhu maksimum. Data pengujian pengaruh panjang stack optimum setiap bahan dapat dilihat pada penurunan suhu total sebelum HHE dioperasikan dan laju transfer kalor pada stack terbaik dari eksperimen. Gambar 9 menunjukkan diagram batang penurunan 
suhu total $\left(\Delta T_{c}\right.$ total) dan variasi daya loudspeaker pada panjang stack optimum masing-masing setiap bahan.

Secara umum, semakin besar daya loudspeaker yang digunakan, semakin cepat pula pemanasan suhu tandon dingin akibat kalor balik. Selain itu, penggunaan daya yang besar, tegangan yang dibutuhkan juga besar dan tekanan dalam tabung resonator semakin besar sehingga mempengaruhi kecepatan molekul gas. Kecepatan molekul gas mempengaruhi laju transfer kalor dari tandon dingin ke tandon panas. Pada Gambar 9 didapatkan daya loudspeaker optimum, yaitu yang menghasilkan penurunan suhu maksimum untuk kedua jenis stack berbeda adalah pada daya $60 \mathrm{~W}$

\section{Kesimpulan dan Saran}

\subsection{Kesimpulan}

Berdasarkan hasil penelitian yang telah dilakukan, dapat disimpulkan bahwa

1 Keberadaan stack dalam tabung resonator sistem pendingin termoakustik gelombang berdiri menyebabkan adanya sedikit pergeseran frekuensi resonansi optimumnya menjadi $(97 \pm 1) \mathrm{Hz}$.

2 Panjang stack setiap bahan mempunyai pengaruh yang berbeda-beda terhadap perubahan suhu. Setiap bahan mempunyai panjang stack optimum yang menghasilkan perubahan suhu maksimum. Pada pendingin termoakustik gelombang berdiri, pengaruh panjang stack terhadap perubahan suhu adalah

(a) Jenis stack gambas memiliki panjang optimum $8 \mathrm{~cm}$ dengan penurunan suhu maksimumnya sebesar $(11,7 \pm 0,1){ }^{\circ} \mathrm{C}$,

(b) Jenis stack batang padi memiliki panjang optimum $8 \mathrm{~cm}$ dengan penurunan suhu maksimumnya sebesar $(8,1 \pm 0,1){ }^{\circ} \mathrm{C}$,

3 Daya loudspeaker sangat berpengaruh terhadap kinerja sistem termoakustik. Secara umum, semakin besar daya loudspeaker, maka semakin besar pula perubahan suhunya, baik di tandon dingin maupun tandon panas. Pada pendingin termoakustik gelombang berdiri, didapatkan penurunan suhu maksimum terjadi pada daya 60 W untuk masing-masing jenis stack di panjang optimumnya.

\subsection{Saran}

Dari penelitian yang telah dilakukan dapat diberikan saran-saran untuk penelitian selanjutnya, yaitu

1 Perlu dilakukan penambahan variabel dengan memvariasi jenis batang padi maupun gambas yang berbeda-beda terhadap pengaruh perubahan suhu pada sistem termoakustik gelombang berdiri.
2 Perlu adanya penelitian lebih lanjut untuk mengetahui penggunaan jenis batang padi maupun gambas pada gelombang berjalan. Hal ini mengingat bahwa system gelombang berjalan mempunyai kemungkinan kecil adanya arus balik.

Pustaka

1. Biwa, T., Yashiro, Y., Kozuka, M., Yazaki, T. dan Mizutani, U., 2004, Experimental Demonstration of Thermoacoustic Energy Conversion in a Resonator, Phys. Rev. E 69, 066304.

2. Elyanita MS, Setiawan I dan Setio Utomo A B, 2007, Pengaruh Peubah frekuensi dan posisi stack bahan kardus terhadap peubah suhu pada sistem termoakustik, Jurnal Fisika Indonesia No. 33 Vol. XI, Edisi Agustus 2007. ISSN: 1410-2994

3. Haris S Dyatmika, Wahyu Nur Achmadin, Prastowo Murti, I. Setiawan, Agung B S Utomo, 2015, Development of the Thermoacoustic Refrigerator System Using a Stack made of some Stainless Steel Mesh and a Hot Heat Exchanger, Indonesian Journal of Physics vol. 26. no.1, July, 2015

4. Hidayah Q, 2014, Pengaruh Stack berbahan Organik terhadap Perubahan Suhu pada Sistem Pendingin Termoakustik Gelombang Berdiri dan Gelombang Berjalan, Tesis Prodi S2 Fisika FMIPA-UGM

5. Ikhsan S., Agung B.S.U, Andi R.W., Guntur M., 2005, Rancang Bangun Piranti Termoakustik sebagai Pendingin dan Pemanas Udara secara Simultan, Laporan Penelitian Antar Bidang IImu 2005, FMIPA, UGM, Yogyakarta.

6. Ikhsan S., Susilowati, Santi, M.E., Agung B.S.U., 2006, Laporan Penelitian Dosen Muda 2006, UGM, Yogyakarta

7. Ikhsan S., Agung B.S.U., Andi R.W., dan Guntur M., 2007, Rancang bangun piranti termoakustik sebagai pemompa kalor, Sigma Vol.10 No. 1, hal. 25-33.

8. Ikhsan Setiawan, Mitrayana dan Agung B S Utomo, 2010, Pengembangan Pendingin termoakustik Ramah Lingkungan Menggunakan Dua Buah Stack, dimuat dalam proccedings 7th Basic Science National Seminar, 20 Februari 2010 di Universitas Brawijaya Malang, ISBN 978-602-96393-0-8

9. King, G.C., 2009, Vibrations and Waves, John Wiley \& Sons, United Kingdom

10. Romdhiah, I. Setiawan, dan Setio Utomo A B., 2006, Pengaruh Variasi Posisi Stack dan Frekuensi Gelombang Bunyi Terhadap Perbedaan Suhu pada Sistem Termoakustik dengan Bahan Stack Film, Jurnal Fisika Indonesia No. 31 Vol. X, Edisi Desember 2006. ISSN: 1410-2994

11. Russell, D.A. dan Weibull, P., 2002, Tabletop Thermoacoustic Refrigerator for Demonstration, Am. J. Phys. 70, 1231-1233. 
12. Sampurna D, Setiawan I dan A B Setio Utomo, 2007, Studi eksperimen untuk mengetahui pengaruh diameter tabung resonator silindris terhadap kinerja piranti termoakustik, Jurnal Fisika Indonesia No. 33 Vol. XI, Edisi Agustus 2007. ISSN: 1410-2994

13. Setiawan I, Agung B S Utomo, Guntur Maruto dan Andi R Wijaya, 2007, Rancang Bangun Piranti Termoakustik sebagai Pemompa Kalor, SIGMA Vol 10, No 1 Januari, USD Yogyakarta (Terakreditasi Dirjen Dikti No. 39/Dikti/Kep/2004. ISSN: 1410-5888)

14. Swift, G.W., 1988, Thermoacoustic Engines, J. Acoust. Soc. Am. 84, 1145-1180

15. Swift, G.W., 2002, Thermoacoustics: A Unifying Perspective for Some Engines and Refrigerators, Los Alamos National Laboratory, Acoustical Society of America Publications.

16. Tu, Q., Gusev, V., Bruneau, M., Zhang, C., Zhao, L., dan Guo, F., 2006, Experimental and Theoretical Investigation on Frequency Characteristic of Loudspeaker-driven Thermoacoustic Refrigerator, Cryogenics 45, 739-746.

17. Wilhelmus, P. H. M., 2009, Mathematical Aspects of Thermoacoustics, PhD Thesis, Technische Universiteit Eindhoven, The Netherlands.

18. Yazaki, T., Biwa, T., dan Tominaga, A., 2002, A Pistonless Stirling Cooler, Appl. Phys. Lett. 80(1), 157-159.

19. Zoontjens, L., Howard, C.Q., Zander, A.C., dan Cazzolato, B.S., 2005, Development of a Low-Cost Loudspeaker-Driven Thermoacoustic Refrigerator, Proceeding of Acoustics, 9-11 November 2005, Busselton, Western Australia.

20. Zulheldi, Ikhsan Setiawan dan Setio Utomo A B, 2006, Pengaruh Intensitas Bunyi, Jarak Letak Stack dan Diameter Tabung Resonator pada Piranti Termoakustik, Jurnal Fisika Indonesia No. 31 Vol. X, Edisi Desember 2006. ISSN: 1410-2994 